\title{
RNA and DNA Binding Epitopes of the Cold Shock Protein TmCsp from the Hyperthermophile Thermotoga maritima
}

\author{
Konstanze von König ${ }^{1} \cdot$ Norman Kachel $^{1} \cdot$ Hans Robert Kalbitzer $^{1}$ D $\cdot$ Werner Kremer $^{1}$
}

Accepted: 8 October 2020 / Published online: 22 October 2020

(c) The Author(s) 2020

\begin{abstract}
Prokaryotic cold shock proteins (CSPs) are considered to play an important role in the transcriptional and translational regulation of gene expression, possibly by acting as transcription anti-terminators and "RNA chaperones". They bind with high affinity to single-stranded nucleic acids. Here we report the binding epitope of TmCsp from Thermotoga maritima for both single-stranded DNA and RNA, using heteronuclear 2D NMR spectroscopy. At "physiological" growth temperatures of $\operatorname{TmCsp}(\geq 343 \mathrm{~K})$, all oligonucleotides studied have dissociation constants between $1.6\left((\mathrm{dT})_{7}\right)$ and $25.2\left((\mathrm{dA})_{7}\right) \mu \mathrm{M}$ as determined by tryptophan fluorescence quenching. Reduction of the temperature to $303 \mathrm{~K}$ leads to a pronounced increase of affinity for thymidylate $(\mathrm{dT})_{7}$ and uridylate $(\mathrm{rU})_{7}$ heptamers with dissociation constants of 4.0 and $10.8 \mathrm{nM}$, respectively, whereas the weak binding of $T m$ Csp to cytidylate, adenylate, and guanylate heptamers $(\mathrm{dC})_{7},(\mathrm{dA})_{7}$, and $(\mathrm{dT})_{7}$ is almost unaffected by temperature. The change of affinities of $T m \mathrm{Csp}$ for $(\mathrm{dT})_{7}$ and $(\mathrm{rU})_{7}$ by approximately 3 orders of magnitude shows that it represents a cold chock sensor that switches on the cold shock reaction of the cell. A temperature dependent conformational switch of the protein is required for this action. The binding epitope on TmCsp for the ssDNA and RNA heptamers is very similar and comprises $\beta$-strands 1 and 2 , the loop $\beta 1-\beta 2$ as well as the loops connecting $\beta 3$ with $\beta 4$ and $\beta 4$ with $\beta 5$. Besides the loop regions, surprisingly, mainly the RNA-binding motif RNP1 is involved in ssDNA and RNA binding, while only two amino acids, $\mathrm{H} 28$ and W29, of the postulated RNA-binding motif RNP2 interact with the uridylate and thymidylate homonucleotides, although a high affinity in the nanomolar range is achieved. This is in contrast to the binding properties of other CSPs or cold shock domains, where RNP1 as well as RNP2 are involved in binding. TmCsp takes up a unique position since it is the only one which possesses a tryptophan residue instead of a usually highly conserved phenylalanine or tyrosine residue at the end of RNP2. NMR titrations suggest that neither $(\mathrm{dT})_{7}$ nor $(\mathrm{rU})_{7}$ represent the full binding motif and that non-optimal intercalation of W29 into these oligonucleotides blocks the access of the RNP2 site to the DNA or RNA. NMR-experiments with $(\mathrm{dA})_{7}$ suggest an interaction of W29 with the adenine ring. Full binding seems to require at least one single purine base well-positioned within a thymine- or uracil-rich stretch of nucleic acids.
\end{abstract}

Keywords Cold-shock protein · TmCsp · Thermotoga maritima $\cdot$ Single-stranded DNA $\cdot$ Single-stranded RNA $\cdot$ Protein/ ssDNA complex $\cdot$ Protein/RNA complex $\cdot$ NMR spectroscopy $\cdot$ Temperature sensing

\section{Introduction}

When microorganisms experience a sudden decrease in temperature, they suffer from a cold shock. Its most striking characteristic is the impairment of all growth-related

Hans Robert Kalbitzer

hans-robert.kalbitzer@biologie.uni-regensburg.de

$\checkmark$ Werner Kremer

werner.kremer@biologie.uni-regensburg.de

1 Institut für Biophysik und Physikalische Biochemie, Universität Regensburg, 93040 Regensburg, Germany processes within the cell. However, after an acclimatization period, a physiological cold shock response sets in, which allows for growth to be resumed and is therefore considered essential for the survival of unicellular organisms (for a review, see [1,2]). This effect is based on the transient appearance of cold-induced proteins (CIPs). In particular, a subgroup comprising the so-called cold shock proteins (CSPs) is induced to an extreme extent.

CSPs are small, acidic proteins found in a wide variety of Gram-negative and Gram-positive species and are classified together as one family since they possess high sequence homology among each other $(>45 \%)$. They seem to exert 
their biological function by binding to single-stranded nucleic acids, especially RNA. In this way, secondary structures such as hair pins, which are increasingly formed in DNA and RNA at low temperatures, may be destabilized, thus enabling both transcription and translation to continue [3]. Due to their binding to mRNA with low sequence specificity, cold shock proteins are also called 'RNA' chaperones [3]. Because of their homology to the cold shock domains of the eukaryotic Y-box transcription factors, CSPs were originally thought to bind to the Y-box-sequence ATTGG. However, for B. subtilis $\mathrm{CspB}$ (BsCspB) no apparent sequence specificity was found $[4,5]$. More recent experiments have revealed that $B s \mathrm{CspB}$ possesses a strong preference for polypyrimidine ssDNA [5]. Its affinity is highest for thymidylate-rich stretches of DNA and directly correlates with the number of T-bases present [6]. In this respect, $(\mathrm{dT})_{7}$ is sufficient for obtaining nanomolar dissociation constants [7].

The tertiary structures of a number of cold shock proteins have been solved, i.e., of Csp from hyperthermophilic Thermotoga maritima [8], of thermophilic Bacillus caldolyticus [9], or of CspB from mesophilic Bacillus subtilis [10, 11], and of CspA from mesophilic Escherichia coli $[12,13]$. They belong to the OB (oligonucleotide/oligosaccharide binding) fold family, which typically is found in Greek-key $\beta$-barrel proteins. In their primary structures, CSPs contain the sequence motifs RNP1 and RNP2 commonly found in RNA-binding proteins $[14,15]$. Taken together, these structural features further support their role as nucleic acid binding proteins.

The crystal structures of $\mathrm{CspB}$ from the mesophilic Bacillus subtilis $(B s \mathrm{CspB})$ complexed with the hexanucleotide 5'-UUUUUU-3' and the pentanucleotide 5'-GUCUUUA-3' single stranded RNA (ssRNA) were published recently [16]. Here, one CSP is complexed with one ssRNA-molecule. In contrast, the ssDNA $5^{\prime}$-TTTTTT-3' $(\mathrm{dT})_{6}$ is bridging to two $B s \mathrm{CspB}$ molecules in the crystal structure [17]. A solution NMR structure of $B s C s p$ in complex with the ssDNA dT ${ }_{7}$ shows that in solution the binding mode of ssDNA is probably different to that observed in X-ray crystallography [18]. Crystal structures of CSP-nucleotide complexes of hyperthermophilic bacteria have not yet been published.

In this paper we aim to characterize the nucleic acid interactions of the cold shock protein from the hyperthermophilic bacterium T. maritima ( $\mathrm{Tm} \mathrm{Csp}$ ) with both ssRNA and ssDNA oligonucleotides. A thorough analysis was considered necessary because it had been shown that the binding specificity among the different CSPs varies slightly [19]. Cold chock proteins have two main functions after cold shock application, (1) an inhibition of the bulk protein expression and (2) an increased expression of CSPs themselves and other cold shock induced, specific proteins (for a review see e.g. [2]). At the millimolar concentrations of CSPs obtained at cold shock conditions, transcription as well as translation is downregulated completely as studies in cell free systems show [20]. For TmCsp 50\% inhibition of the two processes is obtained at a concentration of $140 \mu \mathrm{M}$. Inhibition can completely be abolished by addition of hepta-2'desoxy-thymidylate (dT) $)_{7}$ that competitively binds to $T m \mathrm{Csp}$ with high affinity [20]. Specific activation of translation by high affinity binding of $E c \mathrm{CspA}$ to the 5'-untranslated region of the CspA mRNA can be observed in cell-free systems at cold shock temperatures largely independent of the coding sequence used [21]. For TmCsp detailed data about the unspecific bulk effects and the sequence specific activation effects are still missing, especially with regard to the question if binding to RNA or DNA involves different amino acid motifs of the protein. Preliminary studies had indicated that $T m$ Csp would be an ideal candidate for such studies since its binding affinity for DNA seemed to be significantly higher than those of other CSPs. Furthermore, it could be deduced that $T m$ Csp appeared to require oligomers comprising seven nucleotides as a minimum binding site.

According to the findings that ssDNA binding by $B s \mathrm{Csp}$ predominantly depends on the base composition of the template and not on the specific base sequence [5], simplified oligonucleotide sequences were used for the experiments presented in the following, which consisted of only one type of nucleotide each.

\section{Results}

\subsection{Nucleotide Binding Properties of TmCsp Monitored by Electrophoretic Mobility Shift Assay (EMSA)}

To investigate which types of nucleotides are recognized as TmCsp substrates, binding studies were performed with a non-radioactive electrophoretic mobility shift assay. Constant amounts of 5'-fluorescein-labeled oligonucleotides were incubated with varying concentrations of TmCsp. In the case of the pyrimidine oligonucleotides $(\mathrm{dT})_{7}$ or $(\mathrm{rU})_{7}$, increasing concentrations of $T m$ Csp resulted in a gradual decrease of the intensity of the band corresponding to the free oligonucleotide, while an additional double band reciprocally appeared in the gel with a smaller electrophoretic mobility (Fig. 1a). Silver-staining of the gels showed that both bands contain protein. From this it was concluded that the shifted bands at high oligonucleotide concentrations correspond to the nucleoprotein complex (data not shown). Complete retardation of the free oligonucleotides occurred at a molar ratio of $T m \mathrm{Csp}:(\mathrm{dT})_{7}$ or $(\mathrm{rU})_{7}$ of $2: 1-2.5: 1$. In contrast, incubation of the cold shock protein with the pyrimidine oligonucleotide $(\mathrm{dC})_{7}$ as well as the purine oligonucleotides $(\mathrm{dA})_{7}$ or $(\mathrm{dG})_{7}$ at a ratio as high as 200:1 (corresponding to $100 \mu \mathrm{M} T m \mathrm{Csp}$ ) did not lead to a band shift 


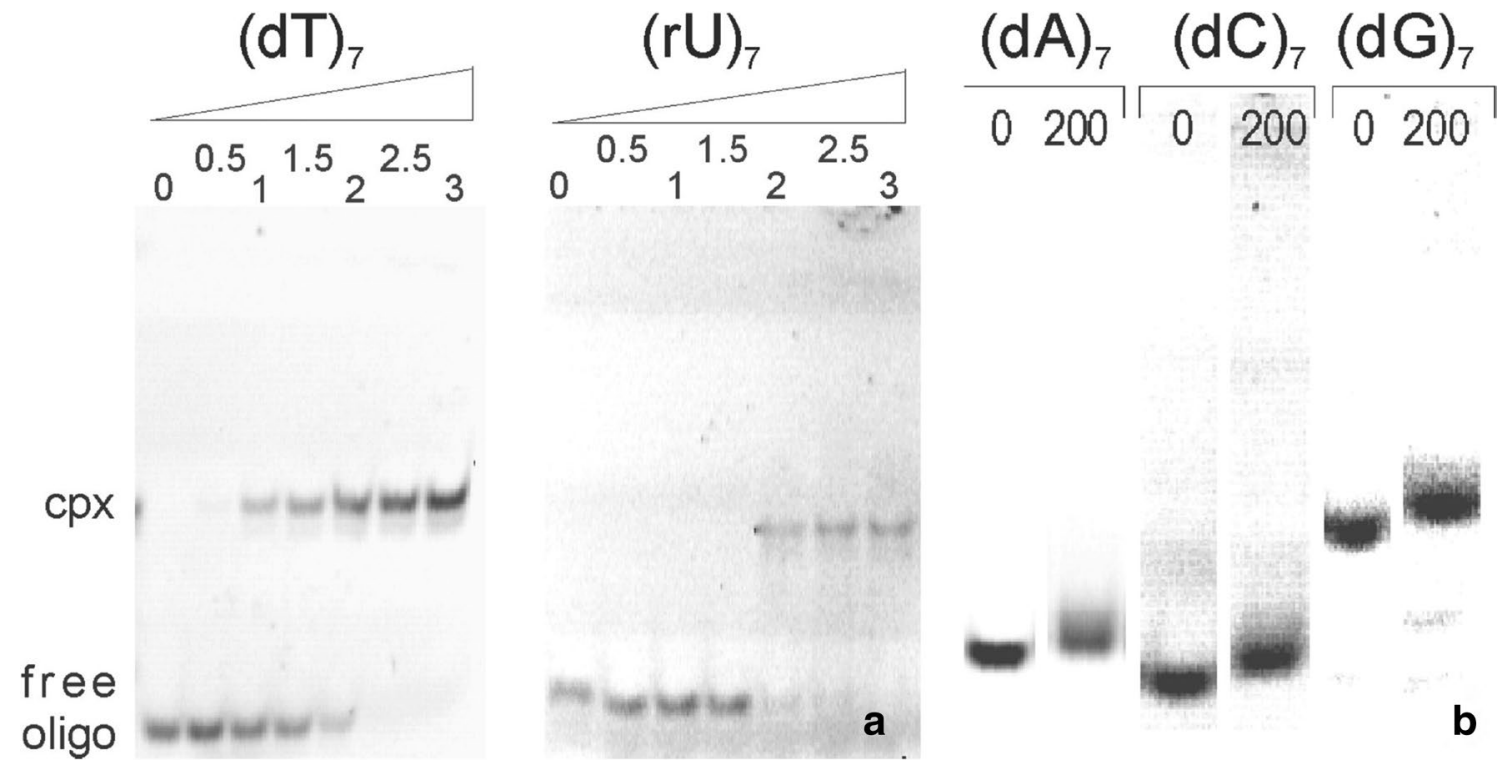

Fig. 1 Relative binding affinities as observed by electrophoretic mobility shift assays. a Gels run after the incubation of $0.5 \mu \mathrm{M}(\mathrm{dT})_{7}$ or $(\mathrm{rU})_{7}$ with $\operatorname{Tm} \mathrm{Csp}$ in different concentrations at room temperature. The molar ratio of protein : oligonucleotide is indicated above the gel. In both cases, good binding interactions were observed. Cpx: Com- plex. b Incubation of $0.5 \mu \mathrm{M}(\mathrm{dA})_{7},(\mathrm{dC})_{7}$ or $(\mathrm{dG})_{7}$ without $T m \mathrm{Csp}$ and with $\operatorname{TmCsp}$ at a ratio of DNA:protein $=1: 200$. Note that the vertical scale was increased by a factor of 2 for visualizing smaller shift changes with addition of Csp. No band could be observed characteristic for complex formation

changes in each titration series, which was clearly reflected in the $1 \mathrm{D}$ spectra.

In the presence of $(\mathrm{dT})_{7}$, the resonances broadened all over the spectrum (including also the signals of nonexchangeable protons). The resonance lines of the $\varepsilon 1$-side chain protons of the tryptophan residues W7 and W29, of the main chain amide proton of V25, and of the high-field shifted $\mathrm{H}^{\delta}$ of $\mathrm{I} 17$ (Fig. 2b) at 10.45, 10.35, 9.77, and -0.146 $\mathrm{ppm}$, respectively, are of special interest since they encountered significant changes upon nucleotide binding which could be easily monitored due to their isolated position. In the first titration step, these signals broadened severely (Fig. 2b). Increased (dT) ${ }_{7}$ concentrations first led to a splitting of the signal of V25 and I17; at high nucleotide concentrations only one downfield shifted signal remains as it is typical for a slow exchange process. A similar process is observed for the tryptophan side chain resonances. At increasing $(\mathrm{dT})_{7}$-concentrations a new downfield shifted resonance at $9.457 \mathrm{ppm}$ and a high field shifted resonance at $10.536 \mathrm{ppm}$ appear and the intensity of the lines corresponding to nucleotide-free Csp simultaneously get weaker. The chemical shifts of these signals are virtually independent of the oligonucleotide concentration as to be expected for slow exchange processes. In slow exchange, the assignment of new resonances is not straightforward without additional information. When during a titration a new peak in close vicinity of the original peak is created and the total integral of the two peaks is constant, one can assume that they correspond to the same residue in the free and complexed form. type of oligonucleotide added, the protein underwent distinct 


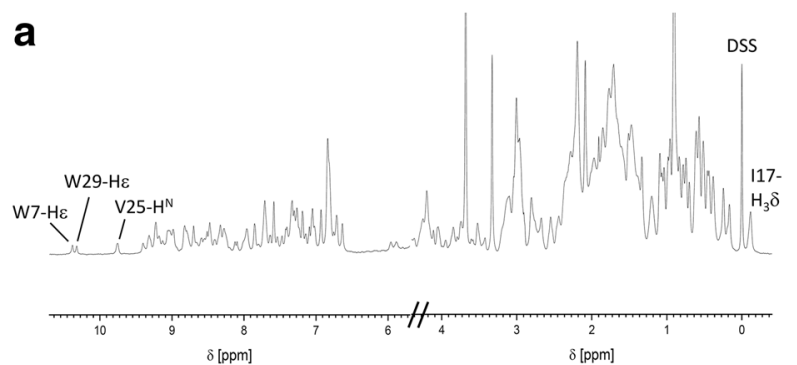

C
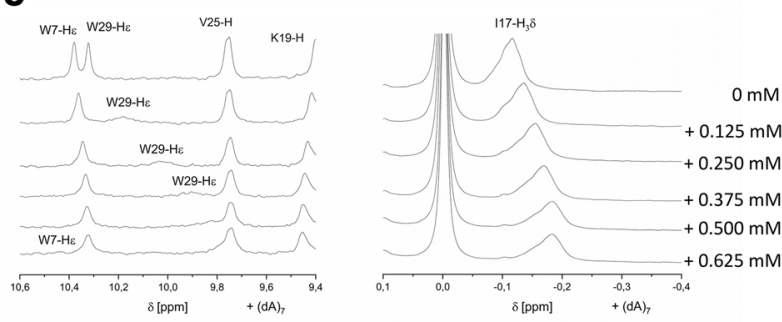

Fig. 2 1D ${ }^{1} \mathrm{H}$ NMR spectra of TmCsp in the absence and presence of ssDNAs. a Overview spectrum of $0.5 \mathrm{mM}$ TmCsp in $50 \mathrm{mM}$ sodium phosphate, pH 6.5, $20 \mathrm{mM} \mathrm{NaCl}, 0.2 \mathrm{mM}$ EDTA, and $0.1 \mathrm{mM}$ DSS at $303 \mathrm{~K}$. b to d $1 \mathrm{mM}$ TmCsp in $50 \mathrm{mM}$ sodium phosphate, $\mathrm{pH} 6.5,20$

With this argument, the downfield shifted signal at $9.81 \mathrm{ppm}$ and the high-field shifted resonance at $-0.17 \mathrm{ppm}$, respectively, can be assigned to the amide proton of V25 and the methyl protons of $\mathrm{I17}$ in the complex. In the $B s \mathrm{CspB}-\mathrm{dT}_{7}$ complex the side chain resonance of W8 (corresponding to W7 in TmCsp) is shifted upfield by approximately $1 \mathrm{ppm}$. By analogy, it is likely that the signal at 9.457 ppm corresponds to $\mathrm{W} 7$ in the TmCsp nucleotide complex and the signal at 10.536 ppm to W29.

Above a molar ratio of approximately 1:2 of $(\mathrm{dT})_{7}: \operatorname{TmCsp}$, the signals of free $T m C$ sp are completely abolished and the integrals corresponding to complexed protein do not change anymore. Consistently, even at the endpoint of the titration with a $(\mathrm{dT})_{7}$ concentration of $1.25 \mathrm{mM}$, the resonance line of W29 is broadened by a factor of 1.25 compared to the oligonucleotide free sample. Note that doubling the molecular mass by dimerization would lead to an increase of the rotational correlation time and thus of the approximate line width by a factor of 1.26.

Titration of $T m \mathrm{Csp}$ with $(\mathrm{dA})_{7}$ leads again to significant spectral changes proving that at the high concentrations used for NMR the oligonucleotide interacts with the protein. When again considering the 4 resonances that were used for monitoring the binding of $(\mathrm{dT})_{7}$, spectral changes are also observed but now typical for fast exchange processes (Fig. 2c). Addition of $(\mathrm{dA})_{7}$ leads to a very small continuous upfield shift of the resonance line of W7 accompanied by a significant line broadening by a factor of 1.8. Similar effects are observed for V25 and Ile17. Both of them are upfield

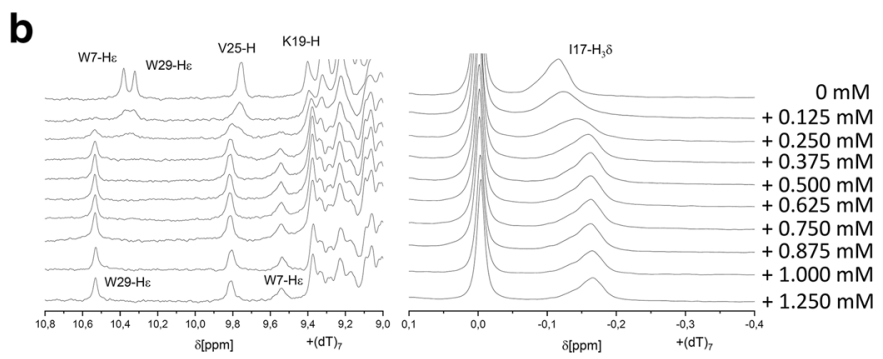

d
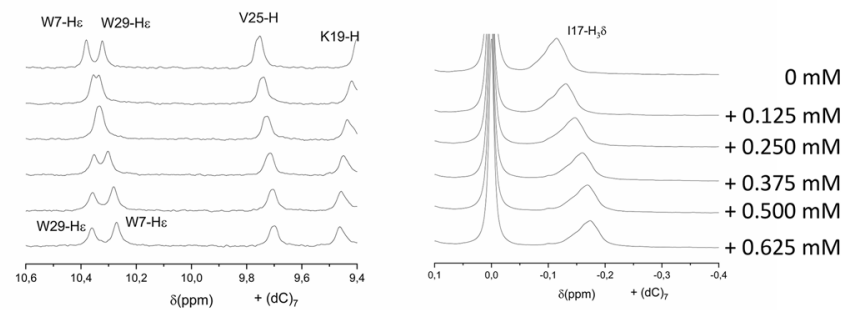

$\mathrm{mM} \mathrm{NaCl}, 0.2 \mathrm{mM}$ EDTA, $0.1 \mathrm{mM}$ DSS, and varying nucleotide concentrations as indicated in the plots. Temperature $303 \mathrm{~K}$. b Spectral changes induced by the addition of $(\mathrm{dT})_{7}, \mathbf{c}$ of $(\mathrm{dA})_{7}$, and $\mathbf{d}$ of $(\mathrm{dC})_{7}$ in varying concentrations as indicated

shifted with increasing nucleotide concentration to positions close to those observed for TmCsp ligated with $(\mathrm{dT})_{7}$. In contrast to the titration with $(\mathrm{dT})_{7}$, the signal of W29 is continuously shifted upfield and severely broadens. At a ratio of approximately 1:0.375 of $\operatorname{TmCsp}:(\mathrm{dA})_{7}$, it is broadened almost beyond detection. In fact, under fast to moderately fast exchange conditions a stronger exchange broadening effect is to be expected for lines with a larger chemical shift difference in the two states involved (nucleotide-free and nucleotide-bound). At oligonucleotide concentrations higher than $0.5 \mathrm{mM}$ a saturation effect is observed for all considered resonances. However, the signal of W29 could not be identified at saturation conditions suggesting an additional heterogeneity of the interaction mode at high oligonucleotide concentrations.

As in case of $(\mathrm{dA})_{7}$ spectra, continuous chemical shift changes are observed when the oligonucleotide $(\mathrm{dC})_{7}$ was added, indicating again a protein-nucleotide interaction, fast on the NMR time scale (Fig. 2d). As with (dA) 7 W7, V25, and $\mathrm{I} 17$ are shifting downfield. However, W29 is downfield shifted as observed in the case of $(\mathrm{dT})_{7}$. No larger exchange broadening is observed, but at the highest DNA concentration used $(0.625 \mathrm{mM})$, the line widths are increased by a factor of 1.3. Again a saturation behavior is observed for all of these amino acids. $(\mathrm{dG})_{7}$ did not yield well-resolved spectra and was therefore omitted from analysis.

In conclusion, these spectral changes indicate interactions of the cold shock protein with all ssDNA fragments studied. It is clear that the extent of the line broadening and 
the changes in chemical shift of the protein resonances upon binding are different. The main difference between the gel shift assays and the NMR spectra shown here are the concentrations used. At the high concentrations used in NMR ( $1 \mathrm{mM}$ protein and $\geq 0.625 \mathrm{mM}$ nucleotide) and the lack of shear force as exerted in EMSA by the electric field, lowaffinity interactions with all oligonucleotides were detectable which could not be detected by the electrophoretic mobility shift assay shown above with oligonucleotide concentrations of $0.5 \mu \mathrm{M}$. Surprisingly, a single oligonucleotide molecule binds two Csp-molecules.

\subsection{Identification of $(\mathrm{dT})_{7}$ and $(\mathrm{rU})_{7}$ Binding Epitopes by Two-Dimensional NMR}

The complex formation was monitored on a residue-by-residue basis by recording a series of ${ }^{1} \mathrm{H}-{ }^{15} \mathrm{~N}$ HSQC fingerprint spectra of ${ }^{15} \mathrm{~N}$-enriched $T m$ Csp samples in the presence of increasing amounts of the oligonucleotides $(\mathrm{dT})_{7}$ or $(\mathrm{rU})_{7}$ at $303 \mathrm{~K}$. Resonance assignments of free TmCsp were performed on the basis of the assignments published by Kremer et al. [8]. The spectral changes due to the addition of oligonucleotide were tracked by comparison of the successively recorded $\left[{ }^{1} \mathrm{H},{ }^{15} \mathrm{~N}\right]$ HSQC spectra (Fig. 3).

Upon complex formation with $(\mathrm{dT})_{7}$, the backbone and side chain amide resonances of the protein in the $\left[{ }^{1} \mathrm{H},{ }^{15} \mathrm{~N}\right]$ HSQC spectra shifted to different extents. In addition, many peaks became undetectable. Such an effect was observed for the amide resonances of $\mathrm{W} 7, \mathrm{D} 9, \mathrm{~S} 10, \mathrm{~K} 12$, G13, Y14, F16, D24, H28, S30, E33, F37, K38, T39, K41, Q51, K54, K55, K63, and V65 (Fig. 4). It could be the effect of strong line broadening by intermediate exchange or it could correspond to the slow exchange effects observed for the $\mathrm{H}^{\varepsilon 1}$ of W7 where the signal in the bound state shifts considerably in the 1D-spectra but cannot be identified unequivocally in the $2 \mathrm{D}$-spectra. The combined chemical shift changes $\Delta \delta_{\text {comb }}$ including the backbone amide nitrogen and proton resonances as well as some side chain resonances are depicted in Fig. 4. Amino acids whose resonances shifted after the interaction with the oligonucleotides $(\mathrm{dT})_{7}$ by more than $\sigma_{0}$ and $2 \sigma_{0}$ were considered moderately and very probable interacting sites, respectively (Fig. 4). The $\left[{ }^{1} \mathrm{H},{ }^{15} \mathrm{~N}\right]$-HSQC spectrum of the complex with $(\mathrm{rU})_{7}$, is much better defined than that with $(\mathrm{dT})_{7}$. As already observed for $(\mathrm{dT})_{7}$ upon complex formation with $(\mathrm{rU})_{7}$, the backbone and side chain amide resonances of the protein in the $\left[{ }^{1} \mathrm{H},{ }^{15} \mathrm{~N}\right] \mathrm{HSQC}$ spectra shifted to different extents. As in the case of $(\mathrm{dT})_{7}$ many peaks became undetectable or shifted considerably. During the titration with $(\mathrm{rU})_{7}$ also significant chemical shift changes $\Delta \delta_{\text {comb }}$ were observed. In most cases they were associated with the same residues as already described for the interaction with (dT) ${ }_{7}$ (Fig. 4). A consensus interacting surface was derived by using only residues that are most likely interacting in at least one of the complexes and in the other structure have at least an intermediate interaction probability (Fig. 4). They are labeled in the consensus plot Co in Fig. 4 in bold letters. These residues are plotted on the NMR structure of TmCsp determined at $303 \mathrm{~K}$ (Fig. 5).

In the complex of Csp with $(\mathrm{rU})_{7}$ many resonances remained either unaffected or shifted continuously with increasing oligonucleotide concentration, indicating that fast or moderately fast exchange conditions prevailed. However, in the presence of $(\mathrm{dT})_{7}$, the chemical exchange rates of many of these resonances of TmCsp behaved in a way which is typical for intermediate exchange or slow exchange on the NMR time scale (Figs. 2, 3, 4). This result reflects most probably that a smaller exchange correlation time of the complex leads to slow exchange conditions. It is also supported by the fact that the overall dissociation constant of $T m$ Csp for $(\mathrm{dT})_{7}$ is 2.7-fold lower than the one for $(\mathrm{rU})_{7}$. An example for slow exchange is shown in Fig. 6a, where the backbone $\mathrm{H}^{\mathrm{N}}$-resonance signal of $\mathrm{W} 29$ in free $T m \mathrm{Csp}$ becomes weaker and broader while simultaneously a new resonance signal of W29 in complex with the oligonucleotide appears and becomes stronger.

In contrast, many resonances in the complex $T m \mathrm{Csp}$ $(\mathrm{rU})_{7}$ show typical fast exchange behavior with continuously shifting cross peaks during the titration, probably since the exchange correlation time is smaller. This is illustrated in Fig. $6 \mathrm{~b}$ for W29 again, where the $\mathrm{H}^{\varepsilon 1}$-resonance of W29 shifts with increasing oligonucleotide concentrations. The $\mathrm{H}^{\varepsilon 1}$-resonance of W7 is strongly broadened at a concentration of $0.125 \mathrm{mM}(\mathrm{rU})_{7}$ already and then disappears completely.

\subsection{Determination of the Dissociation Constants of the TmCsp-RNA/ssDNA-Complexes by Trp Fluorescence Quenching}

The $K_{\mathrm{D}}$ values for the binding of $(\mathrm{dT})_{7}$ and $(\mathrm{rU})_{7}$ by TmCsp were determined by fluorescence quenching titration experiments. Tryptophan residues contribute most to the fluorescence emission spectrum and were used to monitor the binding process. In order to determine the affinities, the protein fluorescence intensity was measured as a function of the oligonucleotide concentration at three different temperatures. The dissociation constants were then calculated from the experimental binding isotherms using a stoichiometry of 2:1. This stoichiometry initially derived from the NMR-data has been confirmed by the fluorescence quenching titration experiments. Titration curves were all monophasic, indicating that the ligands $\left((\mathrm{dA})_{7},(\mathrm{dC})_{7},(\mathrm{dG})_{7},(\mathrm{dT})_{7}\right.$ or $\left.(\mathrm{rU})_{7}\right)$ bound to the two Csp molecules with equal affinity. Hence identical binding sites were assumed in the fit model (Table 1).In line with that, the ligand binding of either $(\mathrm{dA})_{7},(\mathrm{dC})_{7}$, 
Fig. 3 Changes in the $\left[{ }^{1} \mathrm{H}^{-}{ }^{15} \mathrm{~N}\right]-$ HSQC spectrum of ${ }^{15} \mathrm{~N}-T m \mathrm{Csp}$ induced by the oligonucleotides $(\mathrm{dT})_{7}$ and $(\mathrm{rU})_{7}$. The samples contained $1 \mathrm{mM}$ uniformly ${ }^{15} \mathrm{~N}$-enriched TmCsp in $50 \mathrm{mM}$ sodium phosphate, $\mathrm{pH} 6.5,20$ $\mathrm{mM} \mathrm{NaCl}, 0.2 \mathrm{mM}$ EDTA, and $0.1 \mathrm{mM}$ DSS, temperature $303 \mathrm{~K}$. The last step of the titration with the RNA (upper spectrum) and the DNA (lower spectrum) is shown at a ratio of $\operatorname{TmCsp}$ :oligonucleotide $=$ 1:0.625. (top) TmCsp only, (middle) $\mathrm{Tm}$ Csp with $(\mathrm{rU})_{7}$, (bottom) TmCsp with (dT) $)_{7}$ (*), side chain resonances a

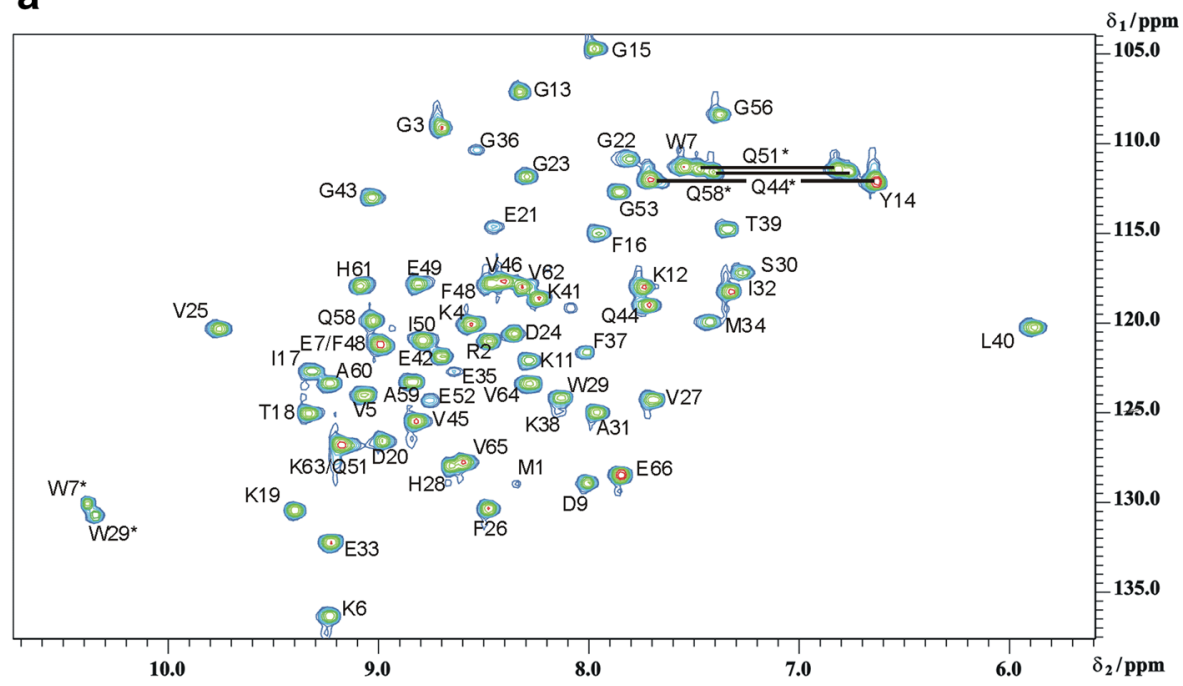

b

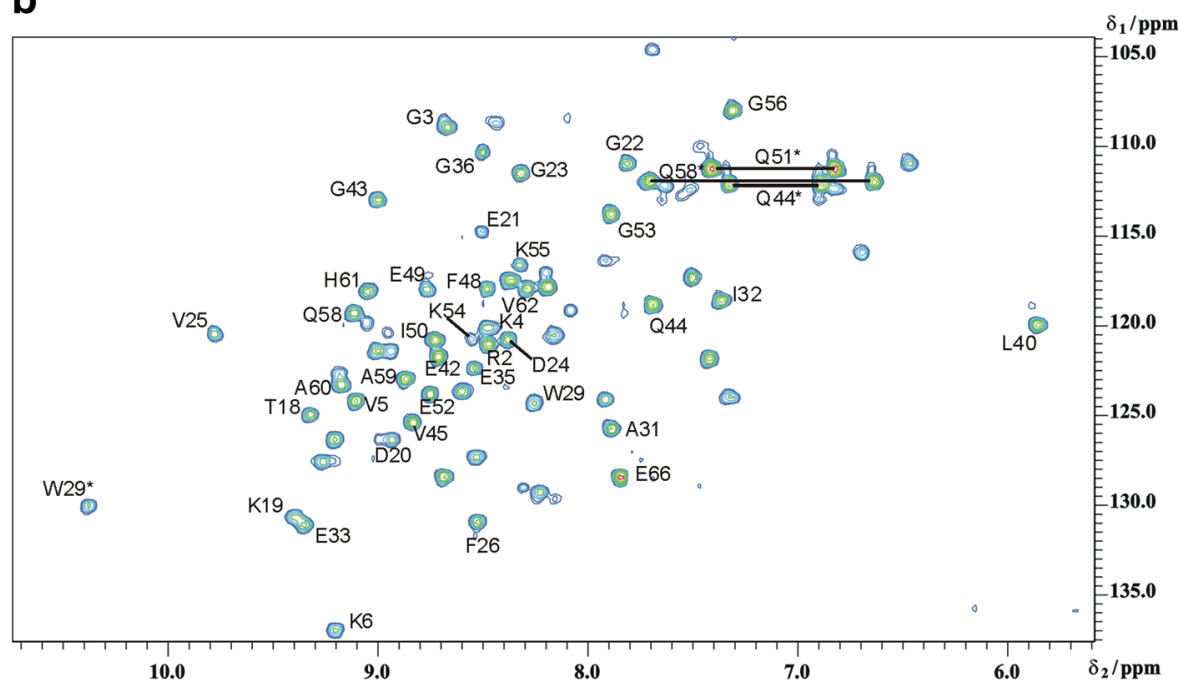

C

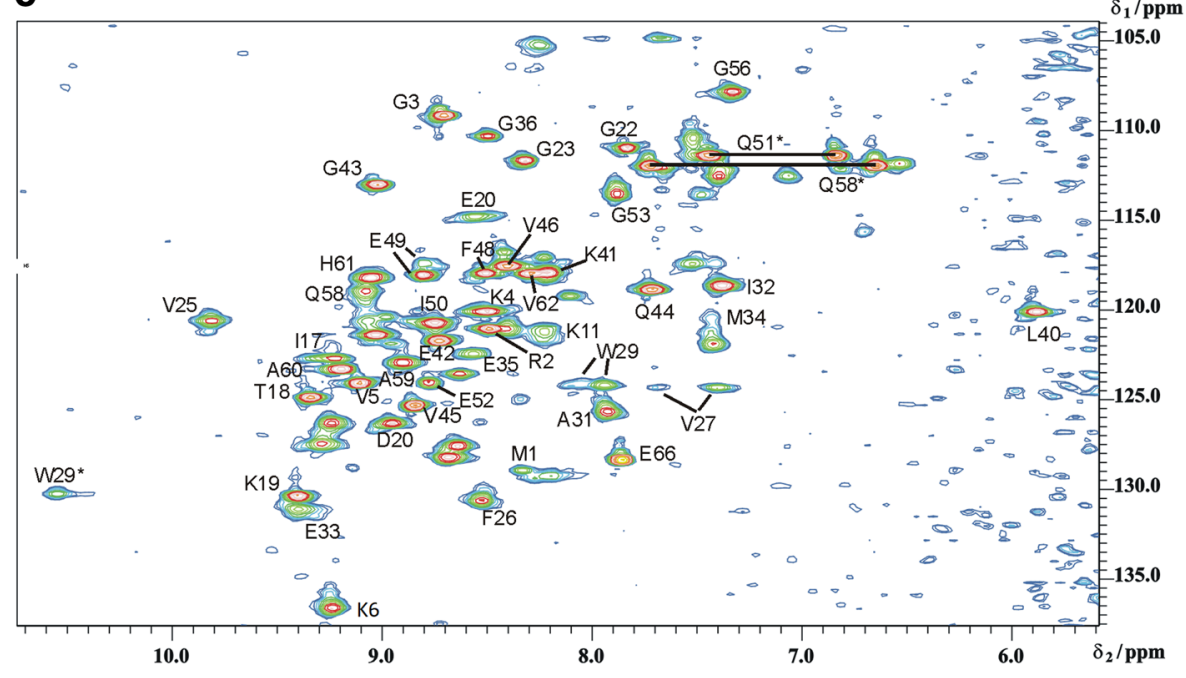


Fig. 4 Residue specific chemical shift perturbations by the oligonucleotides $(\mathrm{dT})_{7}$ and $(\mathrm{rU})_{7}$. The residue and amino acid specific combined chemical shift perturbations $\Delta \delta_{\text {comb }}$ [37] for the (rU) ${ }_{7}$ RNA (top) and (dT) ${ }_{7}$ ssDNA (bottom) were calculated from the 1D and $2 \mathrm{D}$ spectra in the absence of oligonucleotides and in the presence at molar ratios of TmCsp:oligonucleotide $=$ 1:0.625 (dark grey bars). The horizontal lines depict standard deviations $\sigma_{0}$ and $2 \sigma_{0}$. The residues whose unperturbed resonances disappeared in the presence of oligonucleotides and could not be identified in the spectra are presented as light grey bars. Their value was set to $2 \sigma_{0}$. The missing entry in position 57 represents a proline residue (no amide proton). (Middle) In addition, residues are marked as interaction partners in the TmCsp sequence with moderate probability (cursive letters, $\sigma_{0} \geq \Delta \delta_{\text {comb }}<2 \sigma_{0}$ ) and with high probability (bold letters, $\Delta \delta_{\text {comb }} \geq 2 \sigma_{0}$ ). (Co) indicates residues that have high interaction probability for at least one oligonucleotide and moderate to high probability for the second nucleotide. Boxes indicate the limits of $\beta$-strands in TmCsp
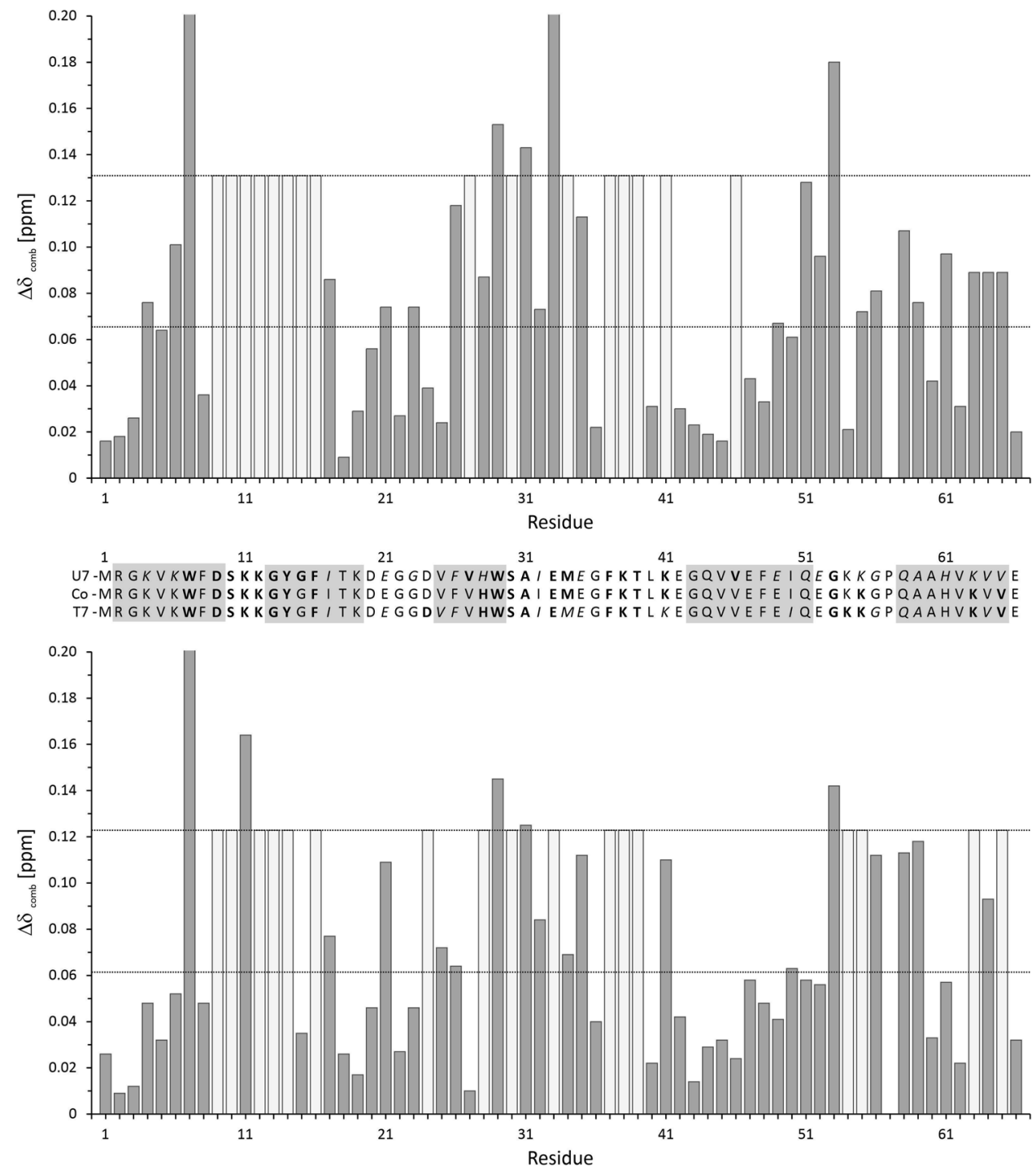
COMRK CO-MRGKVKWFDSKKGYGFITKDEGGDVFVHWSAIEMEGFKTLKEGQVVEFE QQEGKKGPQAAHVKVVE
$(\mathrm{dG})_{7},(\mathrm{dT})_{7}$ or $(\mathrm{rU})_{7}$, does not show any protein NMR peaks characteristic for non-equivalent positions in the two Csp molecules in the complex wit the oligonucleotide. Strikingly, the $K_{\mathrm{D}}$ values for the oligonucleotides shown to be strongly bound in the gel shift assays $\left((\mathrm{dT})_{7}\right.$ and $\left.(\mathrm{rU})_{7}\right)$ ) were in the nanomolar range at $303 \mathrm{~K}$. For all other oligonucleotides the $K_{\mathrm{D}}$ values lay in the micromolar range (Table 1). In addition, the effect of temperature upon binding is very different for different oligonucleotides. At $30{ }^{\circ} \mathrm{C}$, the affinities of the protein for $(\mathrm{dT})_{7}$ were approximately 400 fold higher than at $70{ }^{\circ} \mathrm{C}$, and about 1700 fold higher for $(\mathrm{rU})_{7}$, which is in excellent agreement with the idea that one physiological function of $T m$ Csp is temperature sensing. For $(\mathrm{dA})_{7},(\mathrm{dC})_{7}$ and $(\mathrm{dG})_{7}$, the affinities increased only about $1.5-5$ fold when the temperature was reduced.

\subsection{Stoichiometry of Binding Derived from NMR Spectroscopy}

In principle, NMR spectroscopy allows the quantification of oligonucleotide-protein interactions and the evaluation of different binding models, e.g., cooperative binding or independent binding to several binding sites can be distinguished. Since the $K_{\mathrm{D}}$ values for $(\mathrm{dT})_{7}$ and $(\mathrm{rU})_{7}$ binding as determined by the fluorescence quenching studies are in the nanomolar range and the protein and oligonucleotide concentrations used in the NMR experiments were in the millimolar range, the $K_{\mathrm{D}}$ could be neglected for the quantitative analysis of the chemical shift changes observed during the oligonucleotide titrations (see Eqs. 2, 3 and 4 in Materials and Methods). Figure $7 \mathrm{a}$ shows the normalized chemical shift changes 


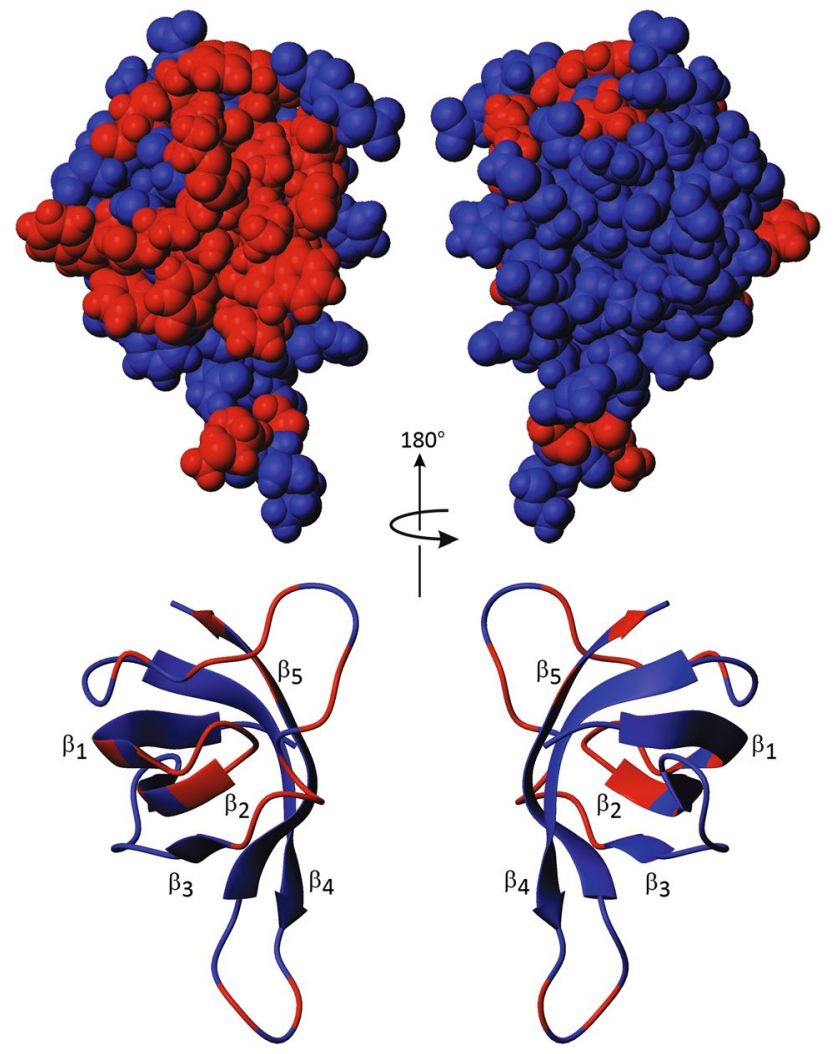

Fig. 5 Mapping of the chemical shift perturbations caused by oligonucleotide binding. Residues that probably are involved (red) or not involved (blue) by oligonucleotide binding (see Fig. 4) were mapped onto the 3D model of pure TmCsp [8]. These representations were generated using the program $M O L M O L$ [35]

for isolated protein signals in $1 \mathrm{D}^{1} \mathrm{H}$ NMR spectra taken from a $(\mathrm{dT})_{7}$ titration experiment with a molar ratio of $(\mathrm{dT})_{7}: \operatorname{Tm} \mathrm{Csp}$ up to $1.25: 1$. The data were fitted by using the $K_{\mathrm{D}}$-values obtained from fluorescence quenching. The saturation effect of the chemical shift change at a ratio of 0.5 indicates a stoichiometry of two molecules $T m$ Csp per $(\mathrm{dT})_{7}$. These chemical shift changes are in perfect agreement with the intensity changes of residues involved in slow exchange described above. We further averaged the normalized ${ }^{1} \mathrm{H}$ and ${ }^{15} \mathrm{~N}$ chemical shift changes of clearly observable resonances in fast exchange obtained from the HSQC titration experiments. The data were fitted using the $K_{\mathrm{D}}$-values from fluorescence quenching for $(\mathrm{dT})_{7}$ and $(\mathrm{rU})_{7}$ and eqs. 2 and 3 . We got values of 1.99 $\pm 0.05\left((\mathrm{dT})_{7}\right)$ and $2.21 \pm 0.04\left((\mathrm{rU})_{7}\right)$, respectively, for the number of independent binding sites $N$. The average maximal chemical shift changes $\Delta \delta^{\text {end }}$, led to $\Delta \delta / \Delta \delta^{\text {end }}$ of $0.93 \pm 0.12\left((\mathrm{dT})_{7}\right)$ and $0.94 \pm 0.10\left((\mathrm{rU})_{7}\right)$, respectively (see Fig. 7a and b). So, the stoichiometry is close to two molecules $T m$ Csp per heptanucleotide.

\section{Discussion}

\subsection{Stoichiometry of Oligonucleotide Binding and Size of the Oligonucleotide Binding Site}

The titration experiments consistently prove that under cold shock conditions ( $303 \mathrm{~K}$ ) two molecules of TmCsp are bound per uridylate or thymidylate heptamer (Figs. 1, 2

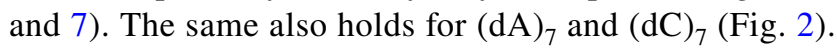
The concentrations of Csp and the oligonucleotides were carefully checked (see Materials and Methods) and could be confirmed directly by NMR spectroscopy.

No hints for a stronger interaction between the two Csp molecules are visible in the NMR spectra. We conclude that their mutual interaction must be very weak or that it must have an internal symmetry leading to equivalent chemical shifts of a given nucleus in the two proteins. As a consequence the length of the oligonucleotide binding site is only 3 nucleotides per Csp (or, alternatively, for a dimer binding to 6 of the 7 nucleotides). In fact, dimerization in the absence of oligonucleotides was observed for $B s \mathrm{CspB}$ in crystals [13] and in solution [22] via strand $\beta 4$, for $S t C s p E$ from Salmonella typhimurium [23]. Most interesting is the interaction of a mutant of $B c \mathrm{CspB}$ from Bacillus caldolyticus [24] through its nucleic acid-binding surface in a point symmetrical arrangement. The latter structures form a symmetric dimer with antiparallel orientation that would lead to the same chemical shifts of nuclei in equivalent positions in the two Csps in the dimer.

When compared with the binding properties of the cold shock proteins from other species, these findings let us suggest that Csp from the hyperthermophilic organism $T$. maritima takes up a unique position because of its unusual origin. It represents a Csp homologue, which previous results cannot be transferred to. For example, chemical shift mapping with CspA from E. coli [12] and CspB from B. subtilis [18] demonstrated that both the RNP1 and the RNP2 motifs strongly contribute to DNA binding. Analysis of the binding stoichiometries showed that the binding sites for $E c \mathrm{CspA}$ and $B s \mathrm{CspB}$ on homogenous templates consist of 6-7 nucleotides per Csp molecule $[5,16]$.

\subsection{Identification of Interaction Sites}

Chemical shift mapping as well as mapping of intensity changes due to slow and intermediate exchange effects show that the location of the binding epitopes for the pyrimidine based ssDNA or RNA oligomers $(\mathrm{dT})_{7}$ and $(\mathrm{rU})_{7}$ on $T m$ Csp do not differ significantly (Figs. 4 and $5)$. The epitope mainly comprises the last amino acids of $\beta$-strand 1 (W7, D9) and the first amino acids of $\beta$-strand 
a

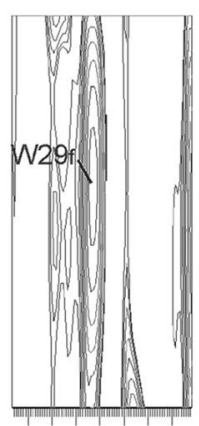

8.3

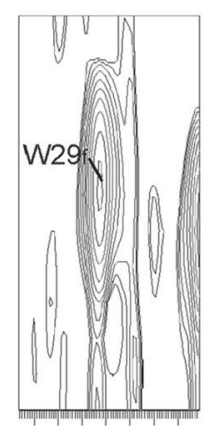

$7.8 \quad 8.3$

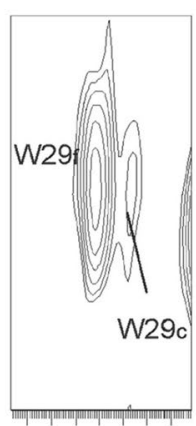

8.3

0

\begin{abstract}
0.125
\end{abstract}
b
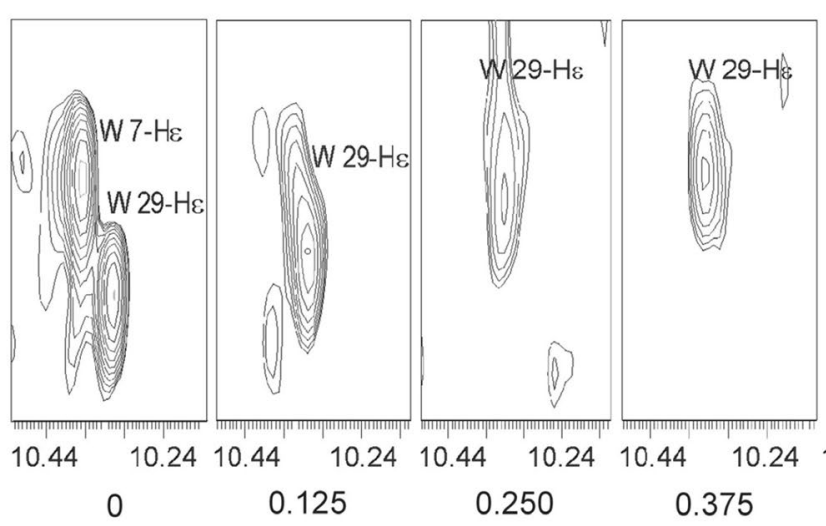
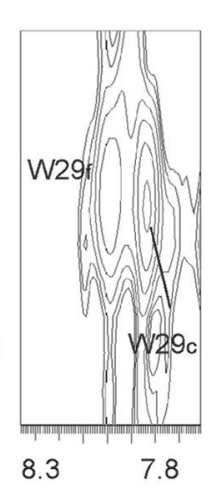

0.500

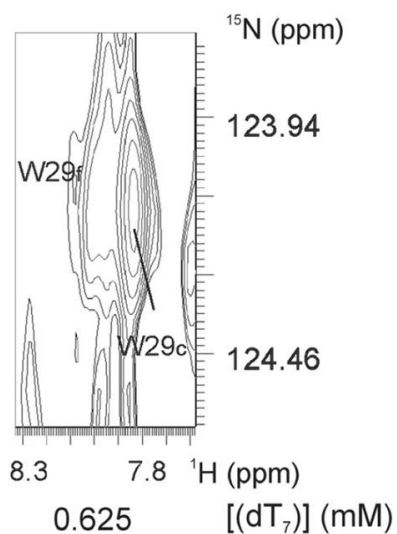

$\left[\left(\mathrm{dT}_{7}\right)\right](\mathrm{mM})$
Fig. 6 Exchange time scales in the complexes $\operatorname{Tm} \mathrm{Csp}-(\mathrm{dT})_{7}$ and TmCsp-(rU) $)_{7} .1 \mathrm{mM}$ uniformly ${ }^{15} \mathrm{~N}$-enriched TmCsp in $50 \mathrm{mM}$ sodium phosphate, $\mathrm{pH} 6.5,20 \mathrm{mM} \mathrm{NaCl}, 0.2 \mathrm{mM}$ EDTA, $0.1 \mathrm{mM}$ DSS, and varying nucleotide concentrations. a Slow exchange of the side chain amide resonance of W29 in the complex with $(\mathrm{dT})_{7}$ : By the addition of $(\mathrm{dT})_{7}$, the signal of the main chain amide proton of $\mathrm{W} 29$

Table 1 Dissociation constants of TmCsp complexed with various nucleotide heptamers at different temperatures

\begin{tabular}{lllc}
\hline $\begin{array}{l}\text { Oligonu- } \\
\text { cleotide }\end{array}$ & $K_{\mathrm{D}}(303 \mathrm{~K})[\mu \mathrm{M}]$ & $\begin{array}{l}K_{\mathrm{D}}(323 \mathrm{~K}) \\
{[\mu \mathrm{M}]}\end{array}$ & $K_{\mathrm{D}}(343 \mathrm{~K})[\mu \mathrm{M}]$ \\
\hline$(\mathrm{dA})_{7}$ & $5.0 \pm 0.2$ & $19.2 \pm 0.5$ & $25.2 \pm 0.6$ \\
$(\mathrm{dC})_{7}$ & $2.8 \pm 0.1$ & n.d. & $11.0 \pm 0.1$ \\
$(\mathrm{dG})_{7}$ & $3.4 \pm 0.1$ & n.d. & $5.6 \pm 0.1$ \\
$(\mathrm{dT})_{7}$ & $(4.0 \pm 0.2) \cdot 10^{-3}$ & $0.44 \pm 0.02$ & $1.6 \pm 0.04$ \\
$(\mathrm{rU})_{7}$ & $(10.8 \pm 0.8) \cdot 10^{-3}$ & $1.52 \pm 0.01$ & $17.4 \pm 0.1$ \\
\hline
\end{tabular}

The dissociation constants were determined by quenching of the tryptophan fluorescence (see Materials and Methods). For data evaluation, two binding sites for TmCsp per heptamer were assumed. $K_{\mathrm{D}}$ is the dissociation constant for one binding site assuming independent binding. $343 \mathrm{~K}\left(70{ }^{\circ} \mathrm{C}\right)$ : physiological temperature of $T$. maritima. $323 \mathrm{~K}\left(50^{\circ} \mathrm{C}\right)$ : temperature range in which the cold shock sets in. 303 $\mathrm{K}\left(30^{\circ} \mathrm{C}\right)$ : cold shock. $n . d$. not determined

2 (G13, Y14, F16) and the loop region in between the two strands (S10, K11, K12). Further interaction points include $\mathrm{H} 28$ and $\mathrm{W} 29$, the last amino acids of strand $\beta 3$, in free $T m \operatorname{Csp}\left(\mathrm{W} 29_{\mathrm{f}}\right)$ disappears, whereas the signal of W29 in complexed $T m$ Csp (W29c) appears simultaneously. b Fast exchange of the main chain amide resonance of W29 in the complex with $(\mathrm{rU})_{7}$ : Interaction with $(\mathrm{rU})_{7}$ leads to a continuous shift of the signals as seen e.g. for the side chain amide proton of W29

and are scattered along the long loop connecting $\beta 3$ and $\beta 4$ (S30, A31, E33, M34, F37, K38, T39, K41), and the loop between $\beta 4$ and $\beta 5$ (G53, K55). In strand $\beta 5$ K63 and V65 see the oligonucleotide binding. Surprisingly, these binding sites only partly involve the classical RNA-binding sites, which had been predicted from the sequence alignment of 23 cold shock domains known from other CSPs and which consists of the motifs RNP1 (residues 13-20) and RNP2 (residues 25-29) [4, 12, 25, 26]. In RNP1 G13, $\mathrm{Y} 14$, and $\mathrm{F} 16$ are concerned, in RNP2 only the aromatic amino acids H28 and W29. Nevertheless, a high binding affinity in the nanomolar range is achieved at cold shock conditions.

Judging from the $K_{\mathrm{D}}$ values and the gel shift assays, the other oligonucleotides interact significantly weaker with $T m$ Csp. Nevertheless at least for the two oligonucleotides $(\mathrm{dA})_{7}$ and $(\mathrm{dC})_{7}$ interactions with $T m \mathrm{Csp}$ can be detected at the high concentrations used in the 1D NMR experiments. A detailed analysis of their binding by 2D-NMR spectroscopy 


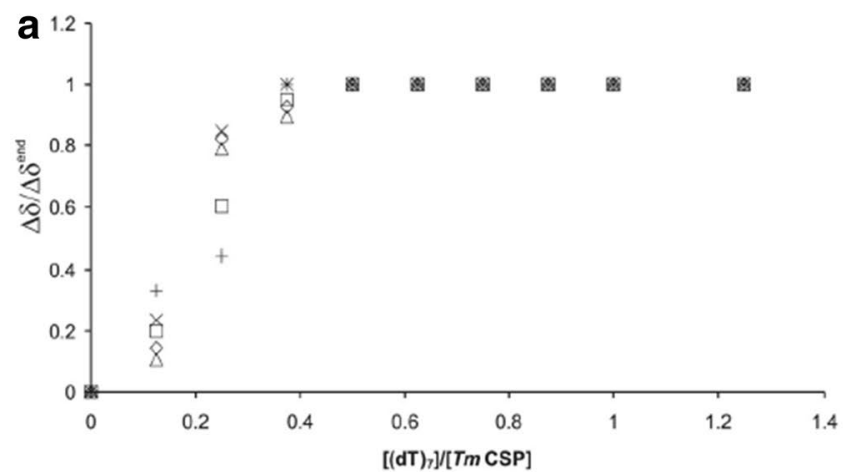

Fig. 7 Stoichiometries of nucleic acid binding from NMR data. a Relative chemical shift change for isolated protein signals in 1D ${ }^{1} \mathrm{H}$ NMR spectra caused by addition of $(\mathrm{dT})_{7}$ (see Fig. 2) indicating a stoichiometry of two TmCsp molecules per $(\mathrm{dT})_{7}$. The chemical shifts were normalized by setting the chemical shift at the high-

has not been performed. Concerning the side chains of the two tryptophan residues qualitatively the same behavior is observed, both nucleotides influence the shifts of the $\mathrm{H}^{\varepsilon 1}$-resonance of W7 and W29, but size and direction of the shifts vary considerably. A moderate downfield shift of the $\mathrm{H}^{\varepsilon 1}$-resonance of W29 is induced by $(\mathrm{dT})_{7}$ and a small upfield shift by $(\mathrm{dC})_{7}$ but a large upfield shift is caused by binding of $(\mathrm{dA})_{7}$ (Fig. 2). For all three nucleotides upfield shifts of the $\mathrm{H}^{\varepsilon 1}$-resonances of $\mathrm{W} 7$ are observed, a very large shift for $(\mathrm{dT})_{7}$, a moderate shift for $(\mathrm{dC})_{7}$, and a very weak shift for $(\mathrm{dA})_{7}$. This suggests that the two tryptophan residues take part in the recognition of the thymine-base. If the shifts of the tryptophan $\mathrm{H}^{\varepsilon 1}$-resonances are mainly ring-current shifts by the bases, it indicates that thymine is optimally oriented relative to the tryptophan residues and that also the adenine ring has to come close to W29 but with an orientation different from the pyrimidine bases.

Under our conditions the binding site of a TmCsp molecule for $(\mathrm{rU})_{7}$ or $(\mathrm{dT})_{7}$ may be only 3 nucleotides long. In consequence, the question arises whether this is true for selected heptapeptides with different nucleotide sequences. Csp from T. maritima is the only one which possesses a tryptophan residue (W29) instead of a highly conserved phenylalanine or tyrosine residue at the end of RNP2 [8]. During the 1D NMR titration experiments, the chemical shift of this residue (W29) changed to different extents according to the kind of oligonucleotide added. The two pyrimidine nucleotides lead to a downfield shift of the $\mathrm{H}^{\varepsilon 1}$-resonance of W29 with a larger shift for $(\mathrm{dT})_{7}$. However, the high-field shift induced $(\mathrm{dA})_{7}$, is much larger and may indicate that in TmCsp this tryptophan favors an interaction with an adenine residue.

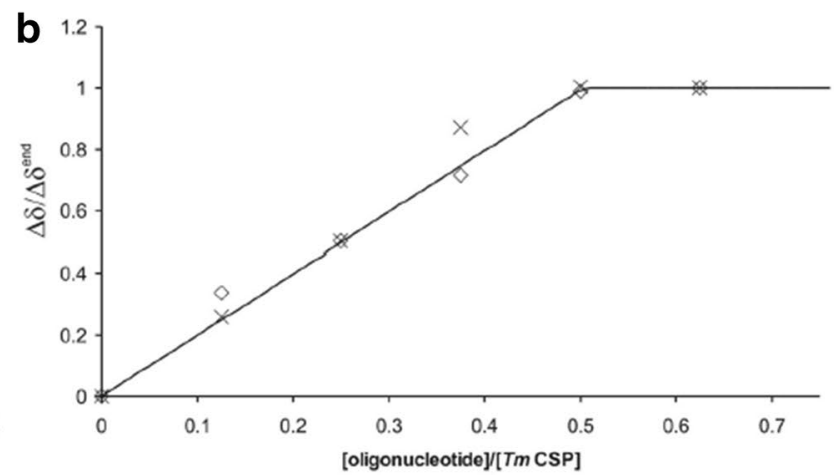

est $(\mathrm{dT})_{7}$.concentration to 1 . b Mean values of the relative chemical shift change taken from HSQC titration experiments (see Fig. 3) with $(\mathrm{dT})_{7}(\diamond)$ and $(\mathrm{rU})_{7}(\mathrm{X})$. The solid line symbolizes the theoretical binding curve as defined by (Eqs. 2 and 4) with $N=2$ and $\Delta \delta / \Delta \delta^{\text {end }}=1$

\subsection{TmCsp as an Important Sensor Switching to the Cold Shock Response}

When discussing the $T m$ Csp-oligonucleotide interaction, it is important to have in mind that Csp itself is part of a temperature sensing system or even may be the main temperature sensor for switching on and off the cold shock response. Under cold shock conditions, cold shock proteins have two different cellular functions, namely (1) the unspecific inhibition of the expression of the majority of proteins at high Csp concentrations and (2) the specific activation of cold chock related proteins (for a review see e. g. [2]). At physiological growing conditions, these regulatory functions should be switched off.

At the millimolar concentrations of Csps present at cold shock conditions transcription as well as translation is downregulated completely as studies in cell free systems show. For TmCsp 50\% inhibition of the two processes is obtained at a concentration of $140 \mu \mathrm{M}$. Inhibition can completely be abolished by addition of the hepta-2'-desoxy-thymidylate $(\mathrm{dT})_{7}$ that competitively binds to $T m \mathrm{Csp}$ with high affinity [20]. This is in line with our binding data since all studied purine and pyrimidine heptanucleotides bind with sufficient micromolar affinity to single stranded RNA and DNA under cold shock conditions (Table 1). Especially, Csp seems to be able to form larger, probably more stable clusters on the nucleotides inhibiting transcription as well as translation. This is in agreement with our study that shows that at cold shock temperatures $T m \mathrm{Csp}$ forms dimers with heptanucleotides. It is most likely that longer nucleotides would also lead to larger nucleoprotein complexes.

The second mechanism, initializing and propagating expression of heat shock related proteins would require recognition of specific nucleotide sequences with high affinity. For this aim the recognition of a sequence motif larger than three nucleotides would be required when only one Csp molecule would bind. However, the problem could be 
solved even with binding of a short sequence of three nucleotides recognized by a single Csp-molecule when more than one Csp would bind cooperatively to a longer nucleotide sequence as observed experimentally in this study.

Generally, a preference for pyrimidine based oligonucleotides was detected for $T m$ Csp as it had been earlier described for $B s C s p[5,6]$. This specificity is rather small at optimal growing conditions where also the affinity of Csp for all nucleotides studied here is quite low (Table 1). However, at cold shock conditions $(303 \mathrm{~K})$ the protein showed a nanomolar affinity for thymidylate or uridylate heptamers but binds with three orders of magnitude lower affinities to purine nucleotides and to the pyridine heptamer $(\mathrm{dC})_{7}$. Under cold shock conditions for the affinity to the ssDNA or RNA templates $(\mathrm{dT})_{7}$ and $(\mathrm{rU})_{7}$ no major differences were observed in line with the dual function of Csp in transcription and translation.

We obtained most of our information concerning the oligonucleotide-Csp interaction at cold shock conditions. The gel shift assays were performed at room temperature with nucleotide concentrations in the nanomolar range $(0.5 \mu \mathrm{M})$ and maximum Csp concentrations of $100 \mu \mathrm{M}\left((\mathrm{dA})_{7},(\mathrm{dC})_{7}\right.$, $\left.(\mathrm{dG})_{7}\right)$ or $1.5 \mu \mathrm{M}\left(\left((\mathrm{dT})_{7},(\mathrm{rU})_{7}\right)\right.$. No clear binding activity was observed with any of the purine based substrates, while $(\mathrm{dT})_{7}$ and $(\mathrm{rU})_{7}$ show strong binding. The NMR titrations were performed at a Csp-concentration of $1 \mathrm{mM}$ at $303 \mathrm{~K}$. Because of this high concentration, they are not suited for a quantitative determination of dissociation constants but for the determination of the stoichiometry of binding (see above). Quantitative binding constants were obtained by fluorescence quenching (Table 1). At $303 \mathrm{~K}$ and Csp concentrations between $5 \mathrm{nM}$ and $1 \mu \mathrm{M}$, the dissociation constants of $(\mathrm{dT})_{7}$ and $(\mathrm{rU})_{7}$ are very small with 4 and $10.8 \mathrm{nM}$, respectively. For $(\mathrm{dA})_{7},(\mathrm{dC})_{7}$, and $(\mathrm{dG})_{7}$ they are approximately 3 orders of magnitude higher with 5.0, 2.8, and 3.4 $\mu \mathrm{M}$, respectively. As a consequence a preferential interaction of Csp with nucleotides containing uracil or thymine is to be expected, although at the typical total concentrations of Csp of $100 \mu \mathrm{M}$ during cold shock [2] also unspecific interactions should occur. At an almost physiological growing temperature for T. maritima of $343 \mathrm{~K}$, the affinity of Csp to the model single stranded is significantly lower. It is very similar for all nucleotides studied here (Table 1) that is the specific recognition of nucleotides is decreased much. Together with the reduced Csp concentration at physiological temperatures, it means that in the cellular environment most of the nucleotide interactions are switched off as observed.

The temperature switch can now be understood from the structural perspective since at high non-cold shock temperatures the interaction with residues interacting specifically with uracil or thymine bases at low temperatures have to be perturbed. Since NMR structures of TmCsp at 303 K [8] and 343 $\mathrm{K}$ [36] are available, we have a structural basis for estimating differences of the cold shock and the physiological state with respect to nucleotide binding. From the chemical shift perturbation $\beta$-strands 1 (W7, D9) and 2 (G13, Y14, F16) and the loop region in between the two strands (S10, K11, K12) appear to be involved in the nucleotide interaction. At cold shock temperatures, the $\mathrm{H}^{\varepsilon 1}$-resonance of $\mathrm{W} 7$ shows very large upfield shift after binding of $(\mathrm{rU})_{7}$ or $(\mathrm{dT})_{7}$ that is not observed for the other oligonucleotides studied here. This suggests that a specific interaction of these two bases with the tryptophan ring exists causing an upfield ring current. At physiological high temperature this region is destabilized, especially a partial melting of $\beta$-strand 1 is observed including amino acids K6 and W7 that characteristically change their orientation in the structure [36]. A second characteristic temperature induced large conformational change was observed for the large loop (E52 to P57) between $\beta$-strand 4 and $\beta$-strand 5 . At $303 \mathrm{~K}$ and $343 \mathrm{~K}$, it adopts a well-defined orientation that differs significantly, at $328 \mathrm{~K}$ an equilibrium between these orientations is observed. Again, significant chemical shift perturbation after binding are observed here (G53, K55).

Directly after switching to low temperature, the Csp concentration is still rather small. Here, even higher affinity and specificity may be required. This suggests that more elaborated nucleic acid sequences may be recognized. It is likely that they contain at least a short sequence of $\mathrm{rU}$ or $\mathrm{dT}$ (probably three units/Csp according to our data). If a longer sequence would be required, the presence of at least one different base in a well-positioned place within the thymidylaterich nucleic acid sequence would make sense. A cytidine is not a likely candidate because of the relative weak response in the NMR-spectra of the Csp (dC) ${ }_{7}$ complex (Fig. 2). One the other hand, the $(\mathrm{dA})_{7}$ has a very strong shift effect on the $\mathrm{H}^{\varepsilon 1}$ resonance of W29 suggesting a stacking interaction of its base with the tryptophan side chain. One can speculate what the recognition site of $T m$ Csp may look like. When we assume that (1) the binding of two TmCsps is preferential, that (2) RNP1 also is a physiological interaction site requiring the pyrimidine nucleotides $\mathrm{dT}$ or $\mathrm{rU}$ in the $\mathrm{TmCsp}$ complex, and that (3) a direct interaction with the purine nucleotide $(\mathrm{dA})_{7}$ and $\mathrm{W} 29$ at the end of RNP2 is proposed from the NMR-data, then a palindromic sequence like AUU UUUUA and UUUAUUU (or ATTTTTTA and TTTATTT in case of DNA binding) would satisfy these conditions.

Since we did not test the oligonucleotide $(\mathrm{dG})_{7}$ by NMR, we cannot exclude that here the guanine base is even more specific. These findings support the notion that W29 plays a major role in the binding process. It is conceivable that in the case of $(\mathrm{dT})_{7}$ or $(\mathrm{rU})_{7}$ some steric hindrance occurs because of the non-optimal intercalation of W29 into these oligonucleotides which blocks the access of the RNP2 site to the DNA or RNA.

Future experiments will include an in vitro selection approach (SELEX) [27] to determine the optimal nucleotide binding sequence for $T m$ Csp. Additionally, a point mutation experiment will be performed, in which W29 will be mutated 
to a phenylalanine or tyrosine residue, which are highly conserved in the sequences of cold shock proteins of most species. In this way we will be able to distinguish whether the dimerization of TmCsp was caused by the use of non-optimal templates, or whether such a short nucleotide sequence represents its true binding site and therefore a new binding mode. The excellent binding affinity found for the pyrimidine templates would argue for the latter possibility.

\section{Conclusion}

At $343 \mathrm{~K}$, close to the physiological temperatures for optimal growth of T. maritima [2] of $353 \mathrm{~K}$, the affinities of all DNA and RNA homopolymers studied is relatively low, indicating that specific cold shock response by $T m$ Csp is switched off. The obtained affinities towards the homopolymers is close to $3.4 \mu \mathrm{M}$ (at $353 \mathrm{~K}$ ) estimated earlier in an in-vitro transcriptiontranslation system for arbitrary genes [20]. Under cold shock conditions the affinities of $(\mathrm{dT})_{7}$ and $(\mathrm{rU})_{7}$ increase by three orders of magnitude, whereas the other oligonucleotides do not change their affinity much. This would perfectly fit to a picture where as specific cold shock response Csp would recognize nucleotide sequences containing poly-U or poly-T, but where the affinity of Csp after its millimolar concentration has been reached is sufficient to inhibit general protein expression. Here also multimerization of the bound Csp molecules could strengthen the inhibitory effect. The specific recognition sequences required for activation of the expression of cold shock induced proteins are not known yet but probably are rich in $\mathrm{rU}$ or $\mathrm{dT}$. From the side of Csp, the unspecific inhibitory effect on protein transcription and translation does not require specific, temperature dependent conformational changes, since even at physiological temperatures its affinity to a variety of sequences is sufficient. However, the specific increase of affinity for poly-U or poly-T sequences under cold shock conditions requires specific conformational changes in the protein that switch on the cold shock response by a strongly increased affinity to the specific recognition sequences, analogous to the dramatic increase of the affinity for $(\mathrm{rU})_{7}$ or $(\mathrm{dT})_{7}$ by three orders of magnitude we observed here.

\section{Materials and Methods}

\subsection{Protein Purification}

For the expression of unlabeled protein, E. coli Rosetta (DE3) pLysS cells transformed with the plasmid coding for TmCsp were grown in Luria Bertani medium in the presence of $50 \mu \mathrm{g} / \mathrm{ml}$ carbenicillin and $68 \mu \mathrm{g} / \mathrm{ml}$ chloramphenicol to an $\mathrm{OD}_{600}$ of 1 , or, for the expression of ${ }^{15} \mathrm{~N}$ isotopically enriched protein, in New Minimal Medium [28] containing $1 \mathrm{~g} / \mathrm{L}^{15} \mathrm{NH}_{4} \mathrm{Cl}$ and $2 \mathrm{~g} / \mathrm{L}$ glucose at $37^{\circ} \mathrm{C}$ to an $\mathrm{OD}_{600}$ of
0.8 , respectively. Expression was induced by adding $1 \mathrm{mM}$ isopropyl $\beta$-D-thiogalactopyranoside, and bacterial growth was continued for $3 \mathrm{~h}$. Purification of the cold shock protein was performed as described [29]: to remove the bulk of the $E$. coli proteins without significant co-precipitation of $T m$ Csp, the cell extract was diluted fourfold with buffer and then heated to $70^{\circ} \mathrm{C}$ for 20 minutes. Pure $T m \mathrm{Csp}$ was obtained by hydrophobic interaction chromatography at $\mathrm{pH}$ 8 and size exclusion chromatography. Its concentration was determined photometrically using an extinction coefficient $\varepsilon_{280}$ of $12,660 \mathrm{M}^{-1} \mathrm{~cm}^{-1}$.

\subsection{Oligonucleotides}

All unlabeled and 5'-fluorescein-labeled ssDNA and RNA oligonucleotides were purchased in HPSF-quality (Highly Purified Salt Free) from MWG Biotech (Ebersberg, Germany) except for the unlabeled RNA, which was purchased from BioSpring (Frankfurt/Main, Germany). The concentrations of the unlabeled oligonucleotides were calculated from their absorbance at $260 \mathrm{~nm}$. The extinction coefficients $\varepsilon_{260}$ used for the individual oligomers were $15,400 \mathrm{M}^{-1} \mathrm{~cm}^{-1}$ for $(\mathrm{dA})_{7}, 7300 \mathrm{M}^{-1} \mathrm{~cm}^{-1}$ for $(\mathrm{dC})_{7}, 11,700 \mathrm{M}^{-1} \mathrm{~cm}^{-1}$ for $(\mathrm{dG})_{7}$, and $8400 \mathrm{M}^{-1} \mathrm{~cm}^{-1}$ for $(\mathrm{dT})_{7}$ and $(\mathrm{rU})_{7}[30]$.

\subsection{NMR Spectroscopy}

NMR samples of unlabeled and uniformly ${ }^{15} \mathrm{~N}$-labeled TmCsp contained $0.5 \mathrm{mM}$ and $1 \mathrm{mM}$ protein, respectively, in $50 \mathrm{mM} \mathrm{NaH}_{2} \mathrm{PO}_{4}$ (pH 6.5), $20 \mathrm{mM} \mathrm{NaCl}, 0.2 \mathrm{mM}$ EDTA (sodium salt), $0.1 \mathrm{mM}$ DSS in ${ }^{1} \mathrm{H}_{2} \mathrm{O} /{ }^{2} \mathrm{H}_{2} \mathrm{O}(92 \% / 8 \%)$, and oligonucleotides in varying concentrations. The NMR experiments were carried out on a Bruker DRX-600 spectrometer $\left({ }^{1} \mathrm{H}\right.$ resonance frequency $600 \mathrm{MHz}$ ) at $303 \mathrm{~K} .{ }^{1} \mathrm{H}-{ }^{15} \mathrm{~N}$ heteronuclear single-quantum coherence (HSQC) spectra [31] were recorded with an echo/anti-echo-gradient selection in $\omega_{1}$ [32], the digital resolution was $4.75 \mathrm{~Hz}$ per point for ${ }^{15} \mathrm{~N}$ and $5.86 \mathrm{~Hz}$ per point for ${ }^{1} \mathrm{H}$.

The proton chemical shifts were referenced to sodium2,2-dimethylsilapentane-5-sulfonic acid (DSS) used as an internal reference. ${ }^{15} \mathrm{~N}$ chemical shifts were referenced indirectly to DSS using an X-value of 0.101329118 [33]. Spectral analysis and peak picking were performed using the program AUREMOL (available at http://www.auremol.de) [34].

\subsection{NMR Data Evaluation}

For the identification of the interaction sites, amino acid and atom specific combined chemical shifts [37] were calculated using the tool implemented in the program AUREMOL (www. auremol.de). The Euclidian norm was used. Note 
that the implementation in AUREMOL in its version from November 2019 now contains weighting factors for all types of atoms in the 20 amino acids (not only the backbone atoms as described in [37]). In our case not only the backbone $\mathrm{N}$ and $\mathrm{H}$ shifts were used but we could also include the effects on the tryptophan $\mathrm{N}^{\varepsilon 1}$ and $\mathrm{H}^{\varepsilon 1}$, as well as the amino groups of the glutamine side chains. The combined chemical shift perturbation can be applied for fast and slow exchange as long as the chemical shifts in the absence and presence of the ligands under saturation conditions are known. If in the slow or intermediate exchange region the chemical shifts in the complex could not be identified, they were treated separately. A significant interaction has been assumed

The probability $P_{A B}$ that a molecule $T m$ Csp is bound to an oligonucleotide is given by (Eq. 1), where $c_{A}$ and $c_{B}$ are the total concentrations of $T m \mathrm{Csp}$ and the heptanucleotide in solution, $N$ is the number of independent binding sites on the heptanucleotide and $K_{\mathrm{D}}$ is the dissociation constant. Equation 1 assumes that there are $N$ independent and equal binding sites.

$P_{A B}=\frac{1}{2 c_{A}}\left(c_{A}+N c_{B}+K_{D}-\sqrt{\left(c_{A}+N c_{B}+K_{D}\right)^{2}-4 N c_{A} c_{B}}\right)$

With $K_{\mathrm{D}}$ in the nanomolar and $c_{A}$ and $c_{B}$ in the millimolar range, Eq. 1 can be simplified to Eq. 2, neglecting $K_{\mathrm{D}}$.

$P_{A B}=\frac{1}{2 c_{A}}\left(c_{A}+N c_{B}-\left|c_{A}-N c_{B}\right|\right)$

For signals under fast chemical exchange regime, the chemical shift $\delta$ is given by (Eq. 3). $\delta_{A}$ and $\delta_{A B}$ are the chemical shifts of free and bound protein. The relative change of the chemical shifts is given by Eq. 4 with $\Delta \delta=\delta-\delta_{A}$ and $\Delta \delta^{\text {end }}=\delta_{A B}-\delta_{A}$.

$\delta=P_{A B} \delta_{\mathrm{AB}}+\left(1-P_{A B}\right) \delta_{A}$

$\frac{\Delta \delta}{\Delta \delta^{\text {end }}}=P_{A B}$

\subsection{Electrophoretic Mobility Shift Assay}

The binding reaction was performed by incubating 7.5 pmol of 5'-fluorescein-labeled ssDNA or RNA with different amounts of protein in NMR buffer $\left(50 \mathrm{mM} \mathrm{NaH}_{2} \mathrm{PO}_{4}\right.$, $\mathrm{pH}$ 6.5, $20 \mathrm{mM} \mathrm{NaCl}$, and $0.2 \mathrm{mM}$ EDTA) at room temperature for $1 \mathrm{~h}$ (total volume $15 \mu \mathrm{l}$ ). Prior to gel electrophoresis, $5 \mu$ of dye solution ( $20 \%$ glycerol, $0.034 \%$ bromphenol blue) were added to the samples. Native gel electrophoresis was performed at $4{ }^{\circ} \mathrm{C}$ in $1 \mathrm{xTBE}$ buffer (5xTBE buffer: $54 \mathrm{~g}$ Tris, $27.5 \mathrm{~g}$ boric acid, $20 \mathrm{ml}$ EDTA $0.5 \mathrm{M})$ through a $20 \%$ mini-polyacrylamide gel at $80 \mathrm{~V}$ until the dye had reached the bottom of the gel (ca. $7 \mathrm{~h}$ ).
The fluorescent oligonucleotides were detected by exposing the gels to UV light $(302 \mathrm{~nm})$. Then the gels were silver-stained to localize the position of the protein.

\subsection{Fluorescence Spectroscopy}

The dissociation constants of $T m$ Csp complexed with various nucleotide heptamers (Table 1) were determined by quenching of the intrinsic tryptophan fluorescence of the nucleoprotein complex as described by Zeeb and Balbach [26] assuming a stoichiometry of two protein molecules bound to one oligonucleotide. Titration experiments at 303 $\mathrm{K}$ were carried out with protein concentrations of $5 \mathrm{nM}$ $\left((\mathrm{dT})_{7}\right), 25 \mathrm{~nm}\left((\mathrm{rU})_{7}\right)$ or $1 \mu \mathrm{M}\left((\mathrm{dC})_{7},(\mathrm{dA})_{7},(\mathrm{dG})_{7}\right)$. For the determination of the $K_{D}$ values at $343 \mathrm{~K} \mathrm{TmCsp} \mathrm{con-}$ centrations of $1 \mu \mathrm{M}\left((\mathrm{dT})_{7},(\mathrm{rU})_{7}\right)$ or $5 \mu \mathrm{M}\left((\mathrm{dC})_{7},(\mathrm{dA})_{7}\right.$, $\left.(\mathrm{dG})_{7}\right)$ were used. The successive addition of oligonucleotides was performed until the protein was fully saturated with the complex partner and no further quenching of the Trp fluorescence was detectable.

Acknowledgements We are grateful to the DFG (Kr1407/4-1) to support this study. We thank Claudia Munte for valuable help in the final stages of the project.

Funding Open Access funding enabled and organized by Projekt DEAL.

Open Access This article is licensed under a Creative Commons Attribution 4.0 International License, which permits use, sharing, adaptation, distribution and reproduction in any medium or format, as long as you give appropriate credit to the original author(s) and the source, provide a link to the Creative Commons licence, and indicate if changes were made. The images or other third party material in this article are included in the article's Creative Commons licence, unless indicated otherwise in a credit line to the material. If material is not included in the article's Creative Commons licence and your intended use is not permitted by statutory regulation or exceeds the permitted use, you will need to obtain permission directly from the copyright holder. To view a copy of this licence, visit http://creativecommons.org/licenses/by/4.0/.

\section{References}

1. Graumann PL, Marahiel MA (1998) A superfamily of proteins that contain the cold-shock domain. Trends Biochem Sci 23:286-290

2. Horn G, Hofweber R, Kremer W, Kalbitzer HR (2007) Structure and function of bacterial cold shock proteins. Cell Mol Life Sci 64:1457-1470

3. Jiang W, Hou Y, Inouye M (1997) CspA, the major cold-shock protein of escherichia coli, is an RNA chaperone. J Biol Chem 272:196-202

4. Schroder K, Graumann P, Schnuchel A, Holak TA, Marahiel MA (1995) Mutational analysis of the putative nucleic acidbinding surface of the cold-shock domain, Cspb, revealed an essential role of aromatic and basic residues in binding of 
single-stranded-DNA containing the Y-Box motif. Mol Microbiol 16:699-708

5. Lopez MM, Yutani K, Makhatadze GI (1999) Interactions of the major cold shock protein of bacillus subtilis CspB with singlestranded DNA templates of different base composition. J Biol Chem 274:33601-33608

6. Lopez MM, Yutani K, Makhatadze GI (2001) Interactions of the cold shock protein CspB from bacillus subtilis with singlestranded DNA. Importance of the $\mathrm{T}$ base content and position within the template. J Biol Chem 276:15511-15518

7. Martin A, Sieber V, Schmid FX (2001) In-vitro selection of highly stabilized protein variants with optimized surface. J Mol Biol 309:717-726

8. Kremer W, Schuler B, Harrieder S, Geyer M, Gronwald W, Welker C, Jaenicke R, Kalbitzer HR (2001) Solution NMR structure of the cold-shock protein from the hyperthermophilic bacterium Thermotoga maritima. Eur J Biochem 268:2527-2539

9. Mueller U, Perl D, Schmid FX, Heinemann U (2000) Thermal stability and atomic-resolution crystal structure of the Bacillus caldolyticus cold shock protein. J Mol Biol 297:975-988

10. Schindelin H, Marahiel MA, Heinemann U (1993) Universal nucleic acid-binding domain revealed by crystal-structure of the bacillus-subtilis major cold-shock protein. Nature 364:164-168

11. Schnuchel A, Wiltscheck R, Czisch M, Herrler M, Willimsky G, Graumann P, Marahiel MA, Holak TA (1993) Structure in solution of the major cold-shock protein from bacillus-subtilis. Nature 364:169-171

12. Newkirk K, Feng W, Jiang W, Tejero R, Emerson SD, Iouye M, Montelione GT (1994) Solution NMR structure of the major cold shock protein (CspA) from escherichia coli: Identification of a binding epitope for DNA. Proc Natl Acad Sci USA 91:5114-5118

13. Schindelin H, Jiang W, Inouye M, Heinemann U (1994) Crystal structure of CspA, the major cold shock protein of escherichia coli. Proc Natl Acad Sci USA 91:5119-5123

14. Bandziulis RJ, Swanson MS, Dreyfuss G (1989) RNA-binding proteins as developmental regulators. Genes Dev 3:431-437

15. Burd CG, Dreyfuss G (1994) Conserved structures and diversity of functions of rna-binding proteins. Science 265:615-621

16. Sachs R, Max KEA, Heinemann U, Balbach J (2012) RNA single strands bind to a conserved surface of the major cold shock protein in crystals and solution. RNA 18:65-76

17. Max KE, Zeeb M, Bienert R, Balbach J, Heinemann U (2006) T-rich DNA single strands bind to a preformed site on the bacterial cold shock protein Bs-CspB. J Mol Biol 360:702-714

18. Zeeb M, Max KEA, Weininger U, Löw C, Sticht H, Balbach J (2006) Recognition of T-rich single-stranded DNA by the cold shock protein Bs-CspB in solution. Nucleic Acids Res 34:4561-4571

19. Lopez MM, Makhatadze GI (2000) Major cold shock proteins, CspA from Escherichia coli and CspB from Bacillus subtilis, interact differently with single-stranded DNA templates. Biochim Biophys Acta - Protein Struct Mol Enzym 1479:196-202

20. Hofweber R, Horn G, Langmann T, Balbach J, Kremer W, Schmitz G, Kalbitzer HR (2005) The influence of cold shock proteins on transcription and translation studied in cell-free model systems. FEBS J. 272:4691-4702

21. Freischmidt A, Hiltl J, Kalbitzer HR, Horn-Katting G (2013) Enhanced in vitro translation at reduced temperatures using a cold-chock RNA motif. Biotech. Lett. 35:389-395

22. Makhatadze GI, Marahiel MA (1994) Effect of pH and phosphate ions on self-association properties of the major cold-shock protein from Bacillus subtilis. Protein Sci 3:2144-2147
23. Morgan HP, Wear MA, McNae I, Gallagher MP, Walkinshaw MD (2009) Crystallization and X-ray structure of cold-shock protein E from Salmonella typhimurium. A Crystallogr Sect F Struct Biol Cryst Commun 65:1240-1245

24. Carvajal AI, Vallejos G, Komives EA, Castro-Fernandez V, Leonardo DA, Garratt RC, Ramırez-Sarmiento CA, Babul J (2017) Unusual dimerization of a BcCsp mutant leads to reduced conformational dynamics. FEBS J 284:1882-1896

25. Kloks CPAM, Spronk CAEM, Lasonder E, Hoffmann A, Vuister GW, Grzesiek S, Hilbers CW (2002) The solution structure and DNA-binding properties of the cold-shock domain of the human Y-box protein YB-1. J Mol Biol 316:317-326

26. Zeeb M, Balbach J (2003) Single-stranded DNA binding of the cold-shock protein $\mathrm{CspB}$ from Bacillus subtilis: NMR mapping and mutational characterization. Prot Sci 12:112-123

27. Tuerk C, Gold L (1990) Systematic evolution of ligands by exponential enrichment - RNA ligands to bacteriophage-T4 Dna-polymerase. Science 249:505-510

28. Budisa N, Steipe B, Demange P, Eckerskorn C, Kellermann J, Huber R (1995) High-level biosynthetic substitution of methionine in proteins by its analogs 2-aminohexanoic acid, selenomethionine, telluromethionine and ethionine in escherichia-coli. Eur J Biochem 230:788-796

29. Welker C, Bohm G, Schurig H, Jaenicke R (1999) Cloning, overexpression, purification, and physicochemical characterization of a cold shock protein homolog from the hyperthermophilic bacterium Thermotoga maritima. Prot Sci 8:394-403

30. Wallace RB, Miyada CG (1987) Oligonucleotide probes for the screening of recombinant DNA libraries. Meth Enzym 152:432-442

31. Palmer AG, Cavanagh J, Wright PE, Rance M (1991) Sensitivity improvement in proton-detected 2-dimensional heteronuclear correlation NMR-spectroscopy. J Magn Reson 93:151-170

32. Schleucher J, Schwendinger M, Sattler M, Schmidt P, Schedletzky O, Glaser SJ, Sorensen OW, Griesinger C (1994) A general enhancement scheme in heteronuclear multidimensional $\mathrm{Nmr}$ employing pulsed-field gradients. J Biomol NMR 4:301-306

33. Markley JL, Bax A, Arata Y, Hilbers CW, Kaptein R, Sykes BD, Wright PE, Wuthrich K (1998) Recommendations for the presentation of NMR structures of proteins and nucleic acids - IUPACIUBMB-IUPAB inter-union task group on the standardization of data bases of protein and nucleic acid structures determined by NMR spectroscopy. Eur J Biochem 256:1-15

34. Gronwald W, Kalbitzer HR (2004) Automated structure determination of proteins by NMR spectroscopy. Progr NMR Spectr 44:33-96

35. Koradi R, Billeter M, Wuthrich K (1996) MOLMOL: a program for display and analysis of macromolecular structures. J Mol Graph 14:51-52

36. Jung A, Bamann C, Kremer W, Kalbitzer HR, Brunner E (2004) High-temperature solution NMR structure of TmCsp. Prot Sci 13:342-350

37. Schumann FH, Riepl H, Maurer T, Gronwald W, Neidig K-P, Kalbitzer HR (2007) Combined chemical shift changes and amino acid specific chemical shift mapping of protein-protein interactions. J Biomol NMR 39:275-289

Publisher's Note Springer Nature remains neutral with regard to jurisdictional claims in published maps and institutional affiliations. 